\title{
Stability Measurements on a 1-T High Temperature Superconducting Magnet
}

\author{
J. W. Lue, L. Dresner, S. W. Schwenterly \\ Oak Ridge National Laboratory, Oak Ridge, TN 37831-8040 USA \\ D. Aized, J. M. Campbell, R. E. Schwall \\ American Superconductor Corporation, Westborough, MA 01581 USA
}

\begin{abstract}
A high temperature superconducting magnet based on Bi-2223 conductor was built at the American Superconductor Corporation. The magnet was constructed by a react and wind technique using conductors made from a metallic precursor process. It has a winding $I D$ of $25.4 \mathrm{~mm}, O D$ of $87.6 \mathrm{~mm}$, and height of 107.3 mm. A heater, two thermometers, and several voltage taps were built into the high field region of the magnet for stability measurements. The magnet generates $1.1 \mathrm{~T}$ central field at $4.2 \mathrm{~K}$ when operating at $1 \mu \mathrm{V} / \mathrm{cm}$ over the entire conductor length,

- including all the joints. Stability measurements were performed in background fiekds up to $2.5 \mathrm{~T}$ from $4.2 \mathrm{~K}$ to $77 \mathrm{~K}$. Stability margins more than 2 orders of magnitude higher than a low temperature superconductor were observed.
\end{abstract}

\section{INTRODUCTION}

As a continuing collaborative effort between Oak Ridge National Laboratory (ORNL) and American Superconductor Corporation (ASC) to develop High Temperature Superconducting (HTS) coils for electric power applications a solenoid magnet was constructed which produces over $1-\mathrm{T}$ field at $4.2 \mathrm{~K}$. The magnet was sized to fit inside the existing $10-\mathrm{cm}$ bore variable temperature dewar at ORNL.

A second goal of the task was to have the magnet instrumented for stability measurements of a HTS coil winding. Namely, heater and voltage taps must be included in the winding to facilitate stability measurements. The magnet was designed, built, and instrumented at ASC and tested successfully from $4.2 \mathrm{~K}$ to $77 \mathrm{~K}$ with background fields of up to $2.5 \mathrm{~T}$ at ORNL.

\section{MAGNET FABRICATION}

The magnet was designed to fit inside the $10-\mathrm{cm}$ bore variable temperature cryostat and a $2.54-\mathrm{cm}$ winding $\mathrm{ID}$ was chosen as small enough to produce the required 1-T field and big enough not to strain-damage the conductor. A react and wind approach was adopted to allow the installation of the instrumentation and ease of applying insulation. This technique permits the use of commercially available insulation material and the selection of conductor with suitable performance level before winding a pancake. The high temperature superconductor used for the magnet winding was $\mathrm{Bi}-2223 / \mathrm{Ag}$ tape manufactured with a

Manuscript received October 18, 1994

Research sponsored by the Office of Energy Efficiency and Renewable Energy, U.S. Department of Energy under contract DE-AC05-840R21400 with Martin Marietta Energy Systems, Inc.
TABLE I

PARAMETERS OF THE 1-TMAGNET

\begin{tabular}{|lll|}
\hline Winding Dimensions & ID & $2.54 \mathrm{~cm}$ \\
& OD & $8.70 \mathrm{~cm}$ \\
& Length & $10.75 \mathrm{~cm}$ \\
Overall Dimensions & ID & $1.90 \mathrm{~cm}$ \\
& OD & $9.65 \mathrm{~cm}$ \\
& Length & $13.70 \mathrm{~cm}$ \\
Tape Conductor & Dimensions & $0.15 \mathrm{~mm} \times 5.33 \mathrm{~mm}$ \\
& Total Length & $575 \mathrm{~m}$ \\
Number of double pancakes & & 9 \\
\hline
\end{tabular}

metallic precursor (MP) process[1]. The conductor made with this process has shown better strain tolerance[2] compared to that manufactured through the oxide power in tube (OPIT) process.

The magnet is made of 9 double-pancakes of the same geometry, placed on top of each other, and connected in series electrically. A total of $575-\mathrm{m}$ of $0.15-\mathrm{mm}$ thick by $5.33-\mathrm{mm}$ wide Bi-2223/Ag tape conductor was used to build the magnet. Table I gives the as-built parameters of the magnet. Fig. 1 shows a picture of the finished magnet.

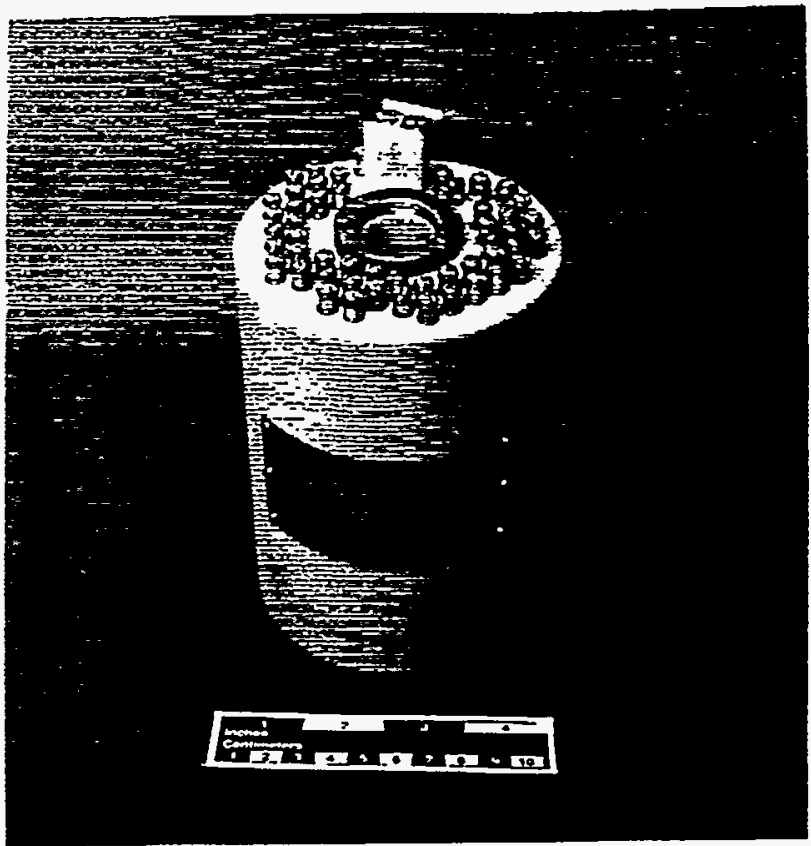

Fig 1 A photograph of the 1-T magnet. The screw heads on the top plate are the terminations of the instrumentation.

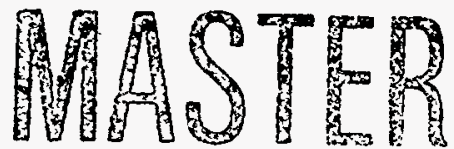




\section{DISCLAIMER}

This report was prepared as an account of work sponsored by an agency of the United States Government. Neither the United States Government nor any agency thereof, nor any of their employees, make any warranty, express or implied, or assumes any legal liability or responsibility for the accuracy, completeness, or usefulness of any information, apparatus, product, or process disclosed, or represents that its use would not infringe privately owned rights. Reference herein to any specific commercial product, process, or. service by trade name, trademark, manufacturer, or otherwise does not necessarily constitute or imply its endorsement, recommendation, or favoring by the United States Government or any agency thereof. The views and opinions of authors expressed herein do not necessarily state or reflect those of the United States Government or any agency thereof. 


\section{DISCLAIMER}

\section{Portions of this document may be illegible in electronic image products. Images are produced from the best available original document.}




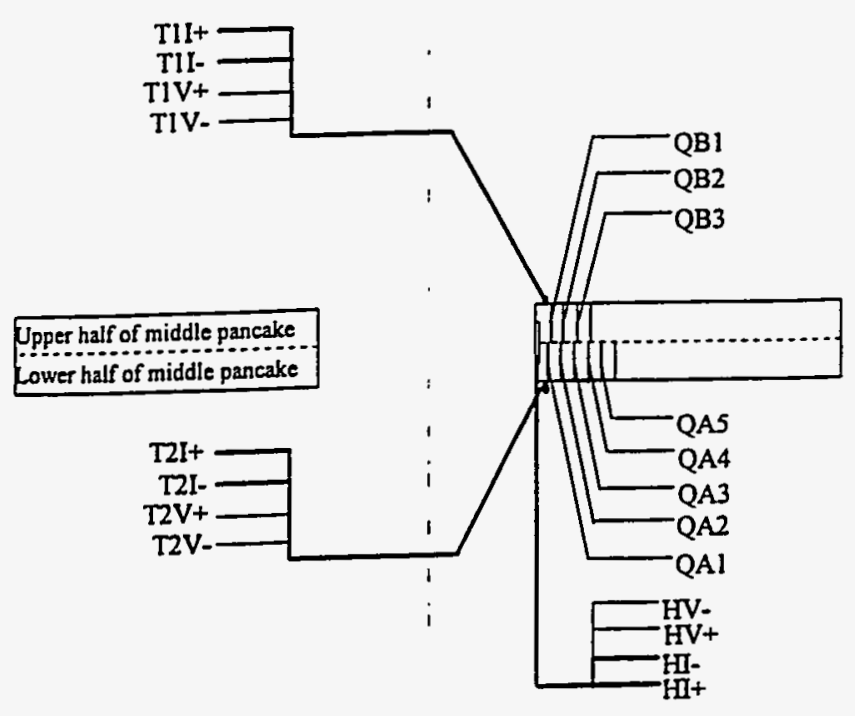

Fig. 2 Instrumentation layout of the center double pancake for the stability measurements. H's: heater, Ts: thermometer, Q's: quench voltage connections.

The center double pancake contains the instrumentation for the stability measurements. A 5- $\Omega$ resistive heater was placed at the crossover between the two pies of the middle double-pancake. It is made of a thermofoil of $0.025-\mathrm{cm}$ thick $\times 0.317-\mathrm{cm}$ wide $\times$ $5.08-\mathrm{cm}$ long, and was sandwiched between the two-tape conductor bundle. Several voltage taps on successive turns near the heater were added to monitor the quench propagation. Two ruthenium oxide (RO) thermometers were also installed near the heater. Fig. 2 shows a sketch of the instrumentation for the stability and quench measurements of the center double pancake.

Voltage taps from each double pancake and strain gages on the OD of the center double pancake were also provided. Terminations of the voltage taps and other instrumentation are located on the top plate as are shown by the screw heads in Fig. 1.

\section{MAGNET PERFORMANCE TESTS}

Electrical tests of the magnet were performed in liquid nitrogen, liquid helium, and gaseous helium from $4.2 \mathrm{~K}$ to $77 \mathrm{~K}$. In addition to the field produced by the magnet itself, background fields of up to $2.5 \mathrm{~T}$ were also applied. A Hall probe measurement at $77 \mathrm{~K}$ found the field factor to be $0.0153 \mathrm{~T} / \mathrm{A}$ at the magnet center. Magnet critical currents, $I_{c}$ of $13.1 \mathrm{~A}$ at $77 \mathrm{~K}$ and $73.2 \mathrm{~A}$ at $4.2 \mathrm{~K}$ in self-field were obtained. $\mathrm{A} 1 \mu \mathrm{V} / \mathrm{cm}$ electric field criterion across the entire conductor length including all the joints was used. At this criterion, the magnet generated $1.12 \mathrm{~T}$ at $4.2 \mathrm{~K}$ and $0.20 \mathrm{~T}$ at $77 \mathrm{~K}$.

Critical currents of the magnet as a function of temperature were determined at different applied background fields and the results are shown in Fig. 3. At $20 \mathrm{~K}$, the $I_{c}$ was $66 \mathrm{~A}$, which generated a $1.0 \mathrm{~T}$ center field. At this current, the engineering current density of the conductor (including both the HTS filaments

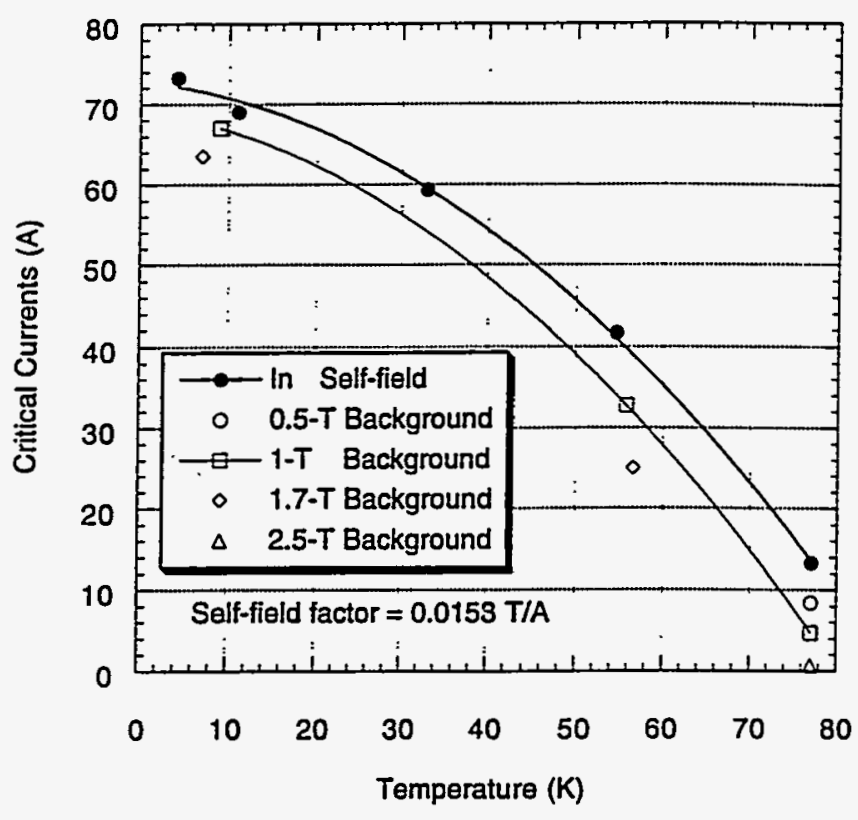

Fig 3 Critical currents of the magnet as a function of temperature at different background fields.

and the $\mathrm{Ag}$ sheath) is $3,900 \mathrm{~A} / \mathrm{cm} 2$, and the current density over the winding space is $2,600 \mathrm{~A} / \mathrm{cm}^{2}$. With a background field of $1 \mathrm{~T}, \mathrm{I}_{c}$ fell to $62 \mathrm{~A}$, which generated an additional $0.95 \mathrm{~T}$ field. No appreciable coil strain was observed during the entire magnet test. Thus the magnet met the goal of generating 1- $T$ field and verified the robust MP conductor in a react-and-wind coil construction.

Voltage taps on the terminals of the double pancakes registered the response of each pancake as the magnet was charged. Fig. 4 shows an example of the V-I curves of half of the

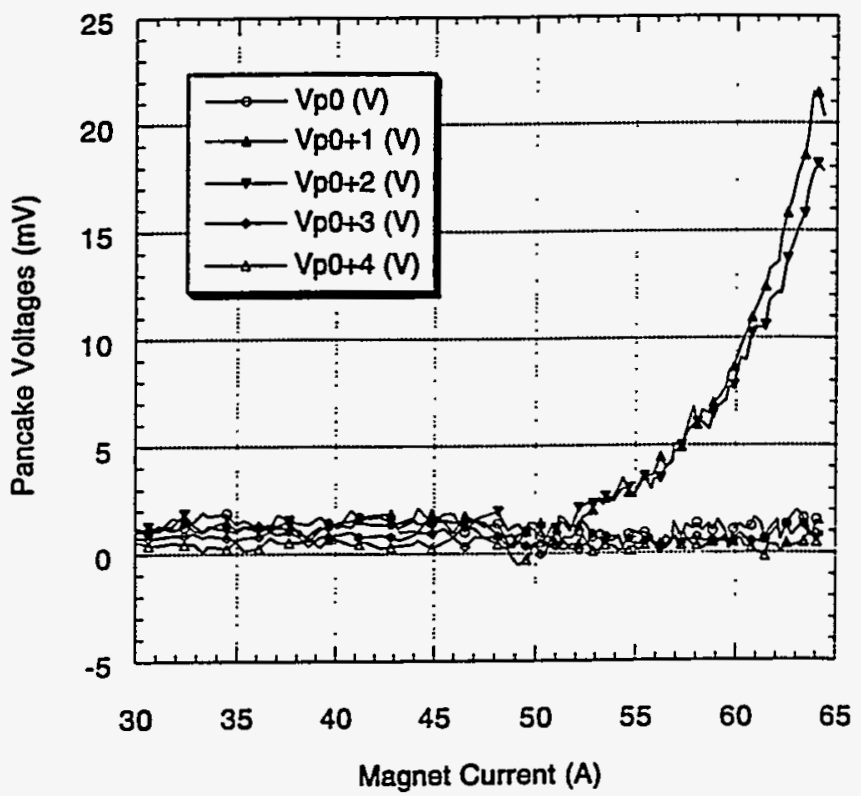

Fig. 4 V-I curves of half of the double pancakes at $30 \mathrm{~K}$, zero background-field. 
double pancakes of the magnet. $V_{p 0}$ is the voltage across the center double pancake and $V_{p 0+i}$ is the voltage across the $i$-th double pancake above the center one. One sees that the V-I curves of the individual double pancakes are quite different. The two double pancakes next to the center one showed resistive voltage first (and have the lower $I_{c}$ ) as the current went up while the rest of the double pancakes barely showed resistive voltage (and have the higher $I_{c}$ ) in this charge. Similar behaviors were seen for the lower half of the magnet. Since there is not a clear physical reason for this behavior of the different pancakes, one can infer this result as mostly due to the different quality of the conductor. If the same electric field criterion of $1 \mu \mathrm{V} / \mathrm{cm}$ was applied to the individual double pancakes, the critical currents of the double pancakes at $4.2 \mathrm{~K}$ in self-field were found to range from $65.9 \mathrm{~A}$ to $90.0 \mathrm{~A}$.

\section{STABILITY MEASUREMENTS}

Stability measurements were performed on the magnet using the instrumentation installed on the center double pancake as shown in Fig. 2. The magnet was first charged to a certain current, a heating pulse was applied to the resistive heater and the voltage and temperature of the magnet near the heater were monitored to observe the recovery or propagation of the normal zone.

Fig. 5 shows an example of the heater current and the heated zone (QAl-QB1) voltage traces in a stability test run. This test shot was made on the magnet at $4.2 \mathrm{~K}$ in $1-\mathrm{T}$ background field. The magnet was charged to $60 \mathrm{~A}$, then a 4-A heater current was pulsed for $150 \mathrm{~ms}$. The heated zone voltage went up and saturated the amplifier at $3.3 \mathrm{mV}$. (The voltage across the pancake indicated it went to $25 \mathrm{mV}$.) After the heat stopped, the heated zone voltage disappeared in about $1 \mathrm{~s}$. In this shot, $12 \mathrm{~J}$

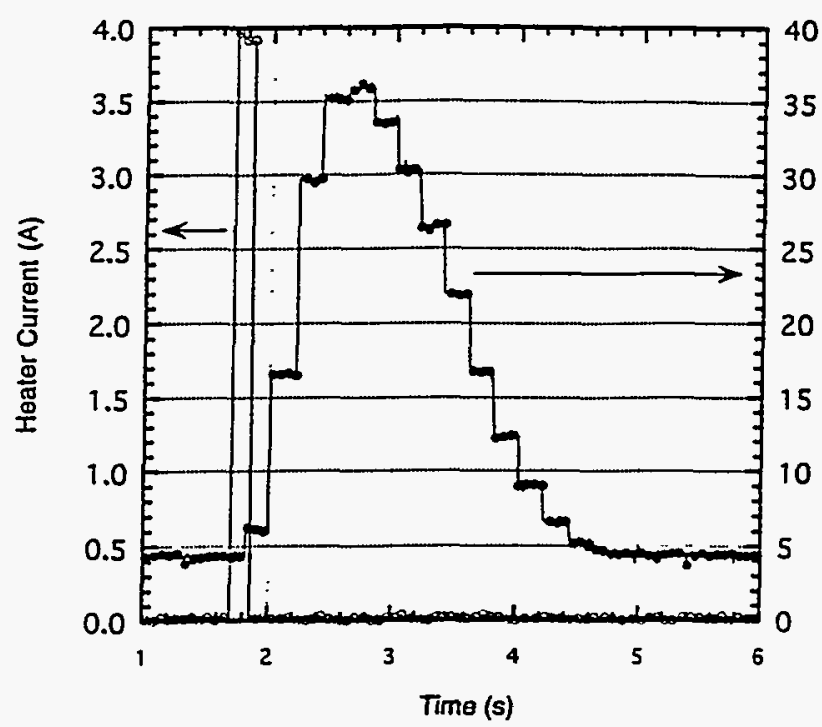

Fig. 6 Temperature excursion of the conductor near the heater in the same test shot as in Fig 5.

of heater energy was applied to the conductor. Since the heater was sandwiched between the two-tape conductor bundle, all of the energy from the heater pulse went to the conductor first. The input energy density on the conductor over the heated length was $150 \mathrm{~J} / \mathrm{cm}^{3}$. Fig. 6 shows that in that same shot the temperature of the conductor near the heater (measured by T2) went up to $36 \mathrm{~K}$. After the heat was removed, the conductor cooled back down to $4.2 \mathrm{~K}$ in a few seconds. Fig. 7 shows the voltage traces of the next two zones (QA2-QA1, QA3-QA2) in that shot.

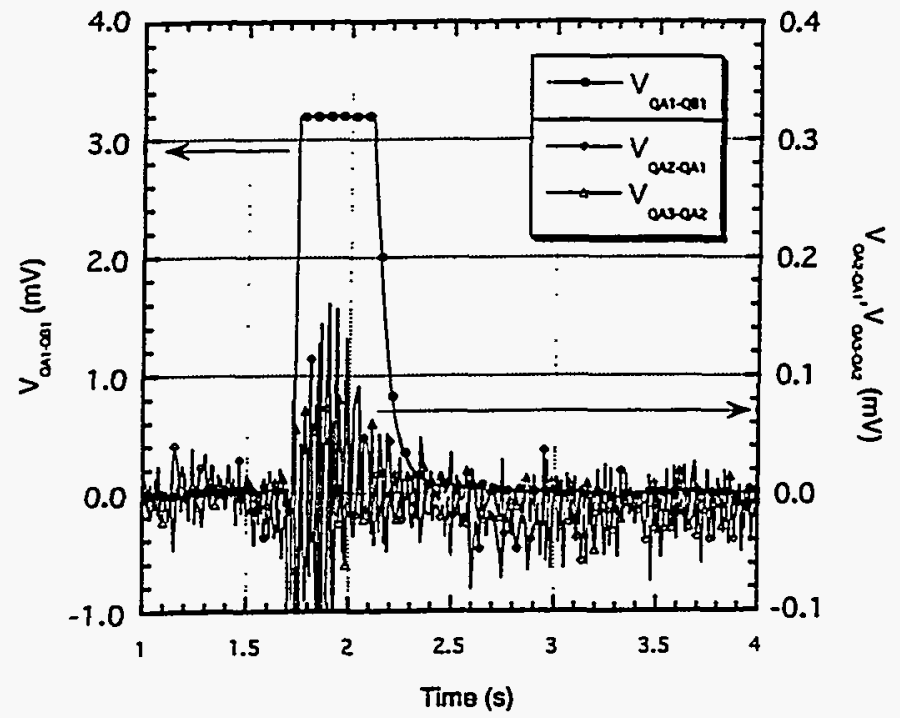

Fig. 7 Voltage traces of the next two zone as compared to the heated zone in the same test shot as in Fig. 5.

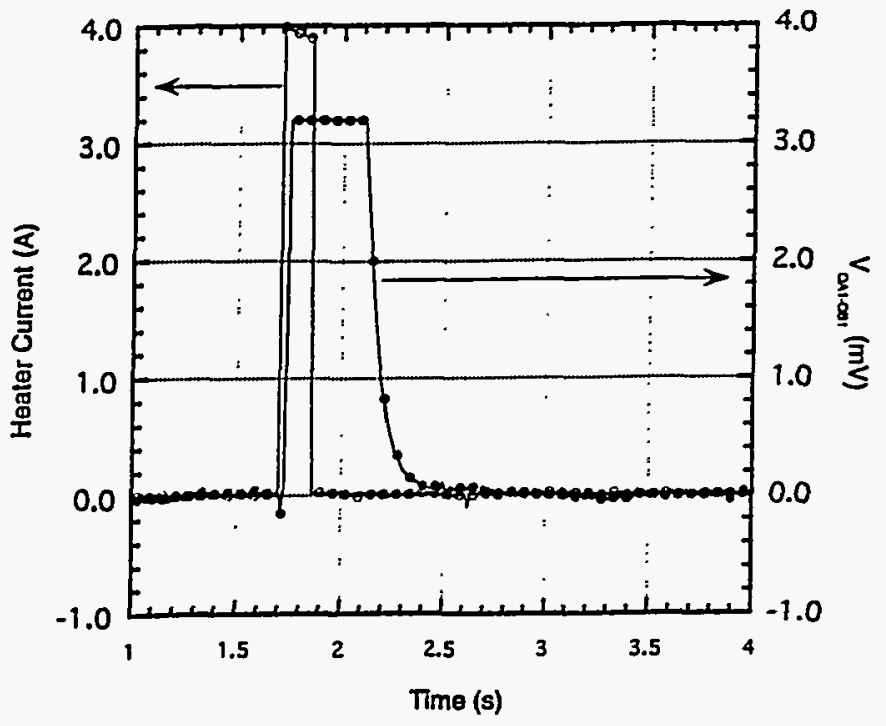

Fig. 5 Heater puise and heated zone voltage traces of a test shot at $4.2 \mathrm{~K}, 1-\mathrm{T}$ 

\author{
same
}


Much smaller voltages ( $\leq 100 \mu \mathrm{V}$ ) were observed in these two zones and they both disappeared before that in the heated zone. It is also seen that the voltages in the adjacent zones appeared just as soon as the heated zone, indicating that they might be due to radial heat conduction rather than a longitudinal propagation along the conductor.

Stability measurements were made from $4.2 \mathrm{~K}$ to $77 \mathrm{~K}$, in background field of up to $2.5 \mathrm{~T}$, and with currents sometimes greater than the critical current defined by the $1 \mu \mathrm{V} / \mathrm{cm}$ criterion. Up to $12 \mathrm{~J}$ of heating energy was applied in $300 \mathrm{~ms}$. No sustained normal zone propagation was observed in any of the tests. This is in line with the predictions of Dresner[3]. Similar nonpropagating normal zone behavior was also reported by Bellis and Iwasa[4]. Thus a lower limit for the thermal stability margin of a HTS conductor was found to be $150 \mathrm{~J} / \mathrm{cm}^{3}-2$ to 3 orders of magnitude higher than a low temperature superconductor [5]. The reason for this high stability margin is thought to be two-fold: 1) - the HTS has a high $T_{c}$ and thus a high temperature margin; therefore it takes more energy to heat it above the current sharing temperature; 2) the HTS has a low n-value (3-8) in the V-I curve, so that the transition to its resistive state is gradual, and the HTS core still shares a good fraction of the current after it goes "normal". Thus, the joule heating is low and the conductor can more easily recover the superconducting state.

One should, however not take these high stability margins of HTS to conclude that a HTS coil will not quench or be burnt out. As is shown in Fig. 4, the individual double pancakes of the present magnet do not behave uniformly, and the conductor in a pancake may not behave uniformly over the entire length either (besides being at different fields). Thus local heating inside a coil

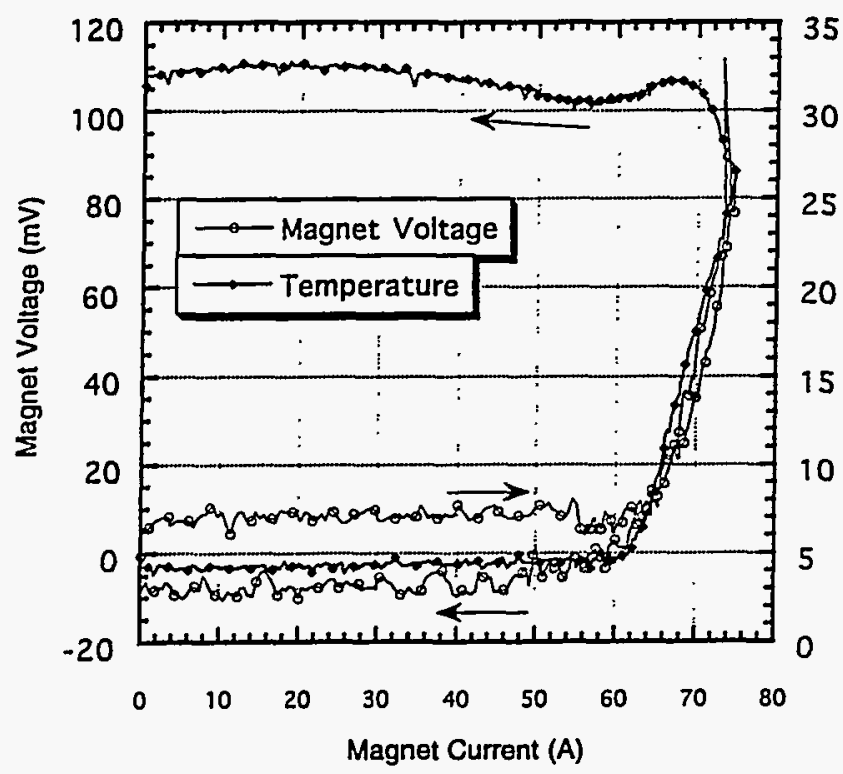

Fig. 8 Magnet voltage and local temperature of the magnet during a curremt charge in gaseous helium. can be expected if the coil is not well cooled by liquid. Fig. 8 shows an example of the temperature of the magnet at T2 during a current charge in gaseous helium. The conductor was at $4.2 \mathrm{~K}$ when the ramp started. It stayed below $5 \mathrm{~K}$ as the current was ramped to $60 \mathrm{~A}$. The magnet voltage stayed essentially zero up to that point (except for the inductive voltage). Thereafter, T2 increased rapidly to $32 \mathrm{~K}$ as the magnet was charged to $75 \mathrm{~A}$ and the magnet voltage went to $110 \mathrm{mV}$. T2 stayed at around $32 \mathrm{~K}$ even when the magnet current was brought back to zero. The total ramp time of that run was 3 minutes. If the magnet current was held at a level above $60 \mathrm{~A}$ (near the critical current), it is conceivable that some local joule heating would continue to heat up the conductor and eventually quench the magnet. As a matter of fact spontaneous quenches [6] were observed in a pancake coil similar to the pancakes of the present magnet.

\section{SUMMARY}

A high temperature superconducting magnet was designed and built by ASC and was successfully tested in the variable temperature cryostat at ORNL from $4.2 \mathrm{~K}$ to $77 \mathrm{~K}$ and with background fields up to $2.5 \mathrm{~T}$. The magnet met all specifications and produced $1 \mathrm{~T}$ self-field at $20 \mathrm{~K}$.

Stability and normal zone propagation experiments were performed on the magnet. No sustained normal zone propagation was observed with the heating induced normal zone. Thermal stability margin of HTS conductor at temperatures from $4.2 \mathrm{~K}$ to $77 \mathrm{~K}$ and fields up to $2.5 \mathrm{~T}$ was found to be more than $150 \mathrm{~J} / \mathrm{cm}^{3}$ -2 to 3 orders of magnitude higher than a low temperature superconductor. One should, however still pay attention to local heating in a HTS winding, if it is not well cooled by liquid and it is desired to operate it close to its critical current.

\section{REFERENCES}

[1] A. Otto et al., "Multifilament Bi-2223 Tapes Made by a Metallic Precursor Route," IEEE Trans. Applied Superconductivity, Vol.3, No.1, p.915, 1993.

[2] A. P. Malozemoff et al., "Progress in the Development of Bismuth-Based High Temperature Superconducting Tapes, "Cryogenics, Vol.32, ICMC Supplement, p.478, 1992.

[3] L Dresner, "Stability and protection of Ag/BSCCO magnets operated in the 20-40 K range," Cryogenies, Vol.33, No. 9, p.900, 1993.

[4] R. H. Bellis and Y. Iwass, "Quench propagation in high $T_{c}$ superconductors," Cryogenios, Vol.34, No. 2, p.129, 1994.

[5] J. W. Lue, "Review of stability experiments on cable-in-conduit conductors, "Cryogenics, in press.

[6] J. W. Lue, L. Dresner, D. Aized, J. M. Campbell, R. E. Schrall, "Quenches in a high temperature superconducting pancake coil," unpublished. 